\title{
Farmer-observed health data around calving-Genetic parameters and association with veterinarian diagnoses in Austrian Fleckvieh cows
}

\author{
A. Koeck, ${ }^{*} \dagger^{1}$ C. Fuerst, ${ }^{*}$ and C. Egger-Danner* \\ *ZuchtData EDV-Dienstleistungen GmbH, Dresdner Strasse 89/19, 1200 Vienna, Austria \\ †Centre for Genetic Improvement of Livestock, University of Guelph, Guelph, Ontario, Canada, N1G 2W1
}

\begin{abstract}
The objective of this study was to investigate if farmer-observed health data around calving can be used together with veterinarian diagnoses for genetic evaluations. Four diseases are recorded by farmers: retained placenta, downer cow syndrome, mastitis, and lameness. Mean disease frequencies were 4.7, 3.8, and $1.8 \%$ for retained placenta, downer cow syndrome, and mastitis, respectively. Lameness had a very low frequency $(0.7 \%)$ and a preliminary analysis revealed a heritability close to zero for this trait. Therefore, lameness was not considered in the analysis. For genetic analyses, univariate and bivariate linear animal models were fitted. Heritabilities for retained placenta, downer cow syndrome, and mastitis were $0.01,0.03$, and 0.003 , respectively. Genetic correlations among the investigated disease traits were low to moderate and not significantly different from zero. Pearson correlations between estimated breeding values for disease traits and other routinely evaluated traits were computed, which revealed mostly favorable relationships to fertility, maternal calving ease, muscling, and longevity. In addition, a moderate favorable association was found between mastitis and somatic cell score. Heritability estimates of farmer-observed health traits were comparable to estimates based on veterinarian diagnoses. Genetic correlations between the investigated diseases based on farmer observations and veterinarian diagnoses were almost 1 , with estimates ranging from 0.98 to 0.99 . These results suggest that farmer recorded health data could be used together with veterinarian diagnoses for genetic evaluations.
\end{abstract}

Key words: disease, farmer observation, veterinarian diagnosis, genetic correlation

Received September 26, 2014

Accepted December 22, 2014

${ }^{1}$ Corresponding author: akoeck@uoguelph.ca

\section{INTRODUCTION}

Health traits are of increasing importance to dairy farmers worldwide. Although the longevity of Austrian Fleckvieh cows is good with an average of $3.82 \mathrm{yr}$ and 3.97 calvings in 2013 , potential exists to reduce expenses. In Austria about 25\% of the cows are culled because of reproductive problems, the same percentage has at least one reproductive disorder per year. Around 15\% of the cows have at least one mastitis diagnosis, and about the same percentage is culled every year because of udder health issues (ZuchtData, 2014).

In Austria, a health monitoring system for cattle started in 2006 in which diagnoses from veterinarians are recorded (Egger-Danner et al., 2010, 2012). A standardized diagnosis key is used, consisting of 10 disease groups covering diseases of calves, diseases of the digestive tract, metabolic diseases, infertility, and disorders associated with parturition, udder diseases, diseases of the claw, and other diseases of the legs, diseases of the respiratory tract, cardiovascular diseases, diseases of the blood and urinary tract, diseases of the central nervous system, skin and infectious diseases, and other diseases. Routine genetic evaluations for the direct health traits mastitis, early reproductive disorders, ovarian cysts, and milk fever were introduced in 2010 for Fleckvieh (Fuerst et al., 2011). Since 2011, recording of direct health traits is compulsory for all breeding herds. The number of farms providing diagnosis data is increasing continuously. Presently diagnostic data from veterinarians are recorded in 13,135 farms, which is about $60 \%$ of all farms under milk recording. However, the percentage varies greatly between regions. Some regions have achieved a very high participation of over $90 \%$, whereas other regions are substantially lower (Egger-Danner et al., 2013). A key factor for success is the continuous promotion of the benefits by convinced opinion leaders (agriculture and veterinarian) in the region.

In Austria the emphasis is put on the further expansion of recording direct health traits. Different projects to promote recording of veterinarian diagnoses as a management tool for veterinarians were initiated. Furthermore, farmers are advised to record health- 
Table 1. Number of records and disease frequencies (\%) for retained placenta, downer cow syndrome, and mastitis based on farmer observations (data set 1$)$

\begin{tabular}{|c|c|c|c|c|c|c|c|c|}
\hline \multirow[b]{2}{*}{ Item } & \multirow[b]{2}{*}{ All } & \multicolumn{7}{|c|}{ Parity } \\
\hline & & 1 & 2 & 3 & 4 & 5 & 6 & $\geq 7$ \\
\hline Records (no.) & 173,805 & 44,633 & 34,362 & 29,445 & 24,035 & 16,526 & 10,814 & 13,990 \\
\hline Retained placenta (\%) & 4.7 & 2.6 & 3.8 & 5.2 & 5.8 & 6.5 & 6.4 & 7.3 \\
\hline Downer cow syndrome $(\%)$ & 3.8 & 0.4 & 0.9 & 3.2 & 6.3 & 8.5 & 9.9 & 9.1 \\
\hline Mastitis (\%) & 1.8 & 1.3 & 1.3 & 1.7 & 2.2 & 2.4 & 2.9 & 3.1 \\
\hline
\end{tabular}

related observations after each calving on a printed form since 2012. Four diseases are recorded (yes/no): retained placenta, downer cow syndrome, mastitis, and lameness. Milk recording technicians transfer these farmer-observed health data around calving (together with calving ease) to the central database at the first test-day after calving.

The objectives of this study were (1) to estimate genetic parameters for farmer-observed health data around calving, (2) to obtain breeding values for farmer observations and examine relationships with routinely evaluated traits, and (3) to determine associations between farmer-observed health data and veterinarian diagnoses in Austrian Fleckvieh cows.

\section{MATERIALS AND METHODS}

\section{Data}

Data Set 1. Farmer-observed health data from Fleckvieh cows calving between May 1, 2012, and December 31, 2013, from Lower Austria and Upper Austria were obtained from ZuchtData (Vienna, Austria). Only herds with at least 5 calvings per year were considered. Sequential edit of cow lactation records (cows with a given lactation record should have records in all previous lactations) was not applied as only data from roughly 2 years was available. The analyzed data set consisted of 173,805 records from 142,994 cows (daughters of 3,422 sires) from 6,079 herds. Retained placenta, downer cow syndrome, mastitis, and lameness were recorded as binary traits $(0=$ healthy, $1=$ diseased $)$. Lameness was not analyzed in the present study, as frequency was very low around calving $(0.7 \%)$ and a preliminary analysis revealed a heritability close to zero for this trait. Summary statistics of the analyzed data are given in Table 1. An animal pedigree file was generated by tracing the pedigrees of cows with records 5 generations back, resulting in 372,669 animals.

Data Set 2. For the subsequent analysis, health observations from data set 1 were merged with records from the health monitoring system. Only cows from herds participating in the health monitoring system were considered. Disease traits from the health monitoring system were defined as binary traits $(0=$ healthy, 1 $=$ at least one diagnosis) based on whether or not the cow had at least one veterinarian diagnosis within the first $10 \mathrm{~d}$ after calving for retained placenta, milk fever, and mastitis. Because downer cow syndrome is not recorded in the health monitoring system, milk fever was used for comparison. In addition, farmer observations and veterinarian diagnoses were considered as the same trait. For example, if a cow had a recorded disease case for retained placenta from the farmer, the veterinarian, or both, the cow was considered diseased, and otherwise healthy. The final data set consisted of 79,193 records from 67,129 cows (daughters of 2,321 sires) from 3,038 herds. Summary statistics of the analyzed data are given in Table 2 . The pedigree of cows with records was traced back 5 generations and consisted of 190,472 animals.

\section{Models}

Data were analyzed with linear animal models using the average information-restricted maximum likelihood (AI-REML) procedure in the DMU package (Madsen and Jensen, 2008). As the assumption of normally distributed data was not fulfilled, threshold models are at least in theory more appropriate to analyze binary

Table 2. Disease frequencies for retained placenta, downer cow syndrome/milk fever, and mastitis based on farmer observations (farmer), veterinarian diagnoses (vet), and combined (farmer+vet; $\mathrm{n}=79,193$ records from 67,129 cows; data set 2)

\begin{tabular}{lccc}
\hline Trait & $\begin{array}{c}\text { Disease frequency (\%) } \\
\text { based on farmer }\end{array}$ & $\begin{array}{c}\text { Disease frequency (\%) } \\
\text { based on vet }\end{array}$ & $\begin{array}{c}\text { Disease frequency (\%) } \\
\text { based on farmer+vet }\end{array}$ \\
\hline Retained placenta & 5.2 & 2.9 & 6.2 \\
Downer cow syndrome/milk fever & 4.1 & 3.0 & 5.3 \\
Mastitis & 2.1 & 2.4 & 3.7 \\
\hline
\end{tabular}


traits. In the present study, linear models were applied, because numerous authors found that linear models are robust toward departures from normality and performed equally well as threshold models (e.g., Negussie et al., 2008b; Koeck et al., 2010b).

Genetic Parameters for Farmer Observations. Bivariate linear animal models were run between retained placenta, downer cow syndrome, and mastitis using data set 1 . The following linear animal model was applied:

$y_{\mathrm{ijklmn}}=\mu+\mathrm{HY}_{\mathrm{i}}+\mathrm{YM}_{\mathrm{j}}+\mathrm{AGE}_{\mathrm{k}}+\mathrm{a}_{\mathrm{l}}+\mathrm{pe}_{\mathrm{m}}+\mathrm{e}_{\mathrm{ijklmn}}$,

where $y_{\mathrm{ijklmn}}$ is the observation for one of the disease traits, $\mu$ is the overall mean, $\mathrm{HY}_{\mathrm{i}}$ is the fixed effect of herd-year of calving ( $\mathrm{i}=1$ to 9,566 ), $\mathrm{YM}_{\mathrm{j}}$ is the fixed effect of year-month of calving ( $\mathrm{j}=1$ to 20$), \mathrm{AGE}_{\mathrm{k}}$ is the fixed effect of age at calving-parity $(k=1$ to 17$), a_{1}$ is the random additive genetic effect $(l=1$ to 372,669$)$, $\mathrm{pe}_{\mathrm{m}}$ is the random permanent environmental effect across lactation $(\mathrm{m}=1$ to 142,994$)$, and $\mathrm{e}_{\mathrm{ijklmn}}$ is the random error term. Six calving age classes were formed for each of the first 2 parities. Age at first calving was grouped into $\leq 26,>26-28,>28-30,>30-32,>32-34$, and $>34 \mathrm{mo}$ and age at second calving was classified into $\leq 39,>39-41,>41-43,>43-45,>45-47$, and $>47$ mo. For older cows, age-parity classes were parities 3 , $4,5,6$, and $\geq 7$.

Breeding Values for Farmer Observations. Breeding values for retained placenta, downer cow syndrome, and mastitis were generated from univariate analyses using data set 1 and model (1). The estimated breeding values were reversed in sign, thus higher breeding values indicate genetically favorable sires with fewer diseased daughters. Pearson correlations between estimated breeding values of sires with at least 30 daughters for retained placenta, downer cow syndrome, and mastitis and official breeding values for routinely evaluated traits were computed to obtain an overview of relationships between traits.

Genetic Correlations Between Farmer Observations and Veterinarian Diagnoses. Bivariate linear animal models were run between disease traits (retained placenta, downer cow syndrome/milk fever, and mastitis) based on farmer observations and veterinarian diagnoses using data set 2. For farmer observations model (1) was fitted, whereas the model for disease traits based on veterinarian diagnoses was as follows:

$$
\begin{aligned}
\mathrm{y}_{\mathrm{ijklmno}}=\mu & +\mathrm{HY}_{\mathrm{i}}+\mathrm{YM}_{\mathrm{j}}+\mathrm{AGE}_{\mathrm{k}}+\mathrm{REC}_{\mathrm{l}} \\
& +\mathrm{a}_{\mathrm{m}}+\mathrm{pe}_{\mathrm{n}}+\mathrm{e}_{\mathrm{ijklmno}}
\end{aligned}
$$

where $y_{\mathrm{ijklmno}}$ is the observation for one of the disease traits, $\mu$ is the overall mean, $H Y_{i}$ is the fixed effect of herd-year of calving ( $\mathrm{i}=1$ to 4,668$), \mathrm{YM}_{\mathrm{j}}$ is the fixed effect of year-month of calving ( $\mathrm{j}=1$ to 20$), \mathrm{AGE}_{\mathrm{k}}$ is the fixed effect of age at calving-parity ( $\mathrm{k}=1$ to 17 ), $\mathrm{REC}_{1}$ is the type of recording ( $1=1$ to 3 ), $\mathrm{a}_{\mathrm{m}}$ is the random additive genetic effect $(\mathrm{m}=1$ to 190,472$), \mathrm{pe}_{\mathrm{n}}$ is the random permanent environmental effect $(\mathrm{n}=1$ to 67,129$)$, and $\mathrm{e}_{\mathrm{ijk} k m n o}$ is the random error term. Age at calving-parity was defined as for model (1). Type of recording was defined in 3 classes: $1=$ less than $25 \%$ of the diagnoses of a farm are electronically transmitted, $2=25$ to $75 \%$ of the diagnoses of a farm are electronically transmitted, and $3=$ more than $75 \%$ of the diagnoses of a farm are electronically transmitted.

Genetic Parameters for Combined Traits. In an additional analysis, farmer observations and veterinarian diagnoses were considered as the same trait. For the combined traits retained placenta, downer cow syndrome/milk fever, and mastitis, model (2) was fitted and univariate linear animal models were run.

\section{RESULTS AND DISCUSSION}

\section{Descriptive Statistics}

Mean disease frequencies were 4.7, 3.8, and $1.8 \%$ for retained placenta, downer cow syndrome, and mastitis (Table 1), respectively, based on farmer observations. Disease frequency of mastitis was low as only a short period around calving is recorded. Frequencies of all 3 diseases were increasing with parity, which was also observed by Heringstad et al. (2005) in Norwegian Red cows.

The phenotypic frequencies in Table 3 show that cows with one of the diseases tended to have a higher frequency of the other diseases. For example, cows with retained placenta had a higher frequency of downer cow syndrome $(9.9 \%)$ than cows without retained placenta $(3.5 \%)$, whereas $12.1 \%$ of the cows having a downer cow syndrome also had a retained placenta.

\section{Genetic Parameters}

Heritabilities and genetic correlations for retained placenta, downer cow syndrome, and mastitis are given in Table 4. Heritability estimates were $0.01,0.03$, and 0.003 for retained placenta, downer cow syndrome, and mastitis, respectively. In a previous study in Austrian Fleckvieh cows, Koeck et al. (2010a) reported a heritability of 0.007 for retained placenta based on veterinarian diagnoses. In Canadian Holstein cows, Koeck et al. (2012) obtained a heritability of 0.03 for retained placenta based on farmer-recorded data. Previously, in 
Table 3. Overall mean disease frequencies (\%) of retained placenta, downer cow syndrome, and mastitis, together with mean disease frequencies for groups of cows with absence (0) or presence (1) of each of the 3 diseases (data set 1)

\begin{tabular}{|c|c|c|c|c|c|c|c|}
\hline \multirow[b]{2}{*}{ Trait } & \multirow{2}{*}{$\begin{array}{c}\text { Overall } \\
\text { mean }\end{array}$} & \multicolumn{2}{|c|}{$\begin{array}{l}\text { Retained } \\
\text { placenta }\end{array}$} & \multicolumn{2}{|c|}{$\begin{array}{l}\text { Downer cow } \\
\text { syndrome }\end{array}$} & \multicolumn{2}{|c|}{ Mastitis } \\
\hline & & 0 & 1 & 0 & 1 & 0 & 1 \\
\hline Retained placenta & 4.7 & & & 4.4 & 12.1 & 4.5 & 13.2 \\
\hline Downer cow syndrome & 3.8 & 3.5 & 9.9 & & & 3.7 & 10.8 \\
\hline Mastitis & 1.8 & 1.6 & 5.1 & 1.7 & 5.1 & & \\
\hline
\end{tabular}

all genetic studies, milk fever was investigated rather than downer cow syndrome, with heritability estimates ranging from 0.01 to 0.04 (Kadarmideen et al., 2000; Neuenschwander, 2010; Fuerst et al., 2011). For mastitis in the period from $7 \mathrm{~d}$ before to $30 \mathrm{~d}$ after calving, Negussie et al. (2008a) estimated a heritability of 0.03 .

Genetic correlations among the investigated disease traits were low to moderate and not significantly different from zero (Table 3). Similar, low to moderate genetic correlations from -0.10 to 0.22 among retained placenta, milk fever, and mastitis were reported by Heringstad et al. (2005).

\section{Associations with Other Routinely Evaluated Traits}

Pearson correlations between sire breeding values for disease traits with selected routinely evaluated traits are shown in Table 5. Routinely evaluated traits in Austria are expressed that a higher breeding value is favorable. Correlations between breeding values are always an underestimation of genetic correlations, unless accuracies of estimated breeding values are close to 1 . Thus, these results should only be interpreted as general indications.

An unfavorable relationship was observed between milk yield and mastitis, which is in agreement with previous studies (e.g., Negussie et al., 2008a). As expected, SCS was favorably correlated with mastitis.

In previous studies, low to moderate favorable genetic correlations were reported between health and fertility traits (e.g., Holtsmark et al., 2008; Onyiro et al., 2008). Also in the present study, mostly favorable associations were found between the investigated disease traits and calving to first service, 56-d nonreturn rate, and first service to conception. This indicates that cows with more health problems after calving have longer intervals to first ovulation and first estrus, lower first service conception rates, and more days open. Based on Austrian conditions, Stocker (2008) calculated a loss of at least $€ 125$ per cow for 1 mo of extended interval between calving.

Maternal calving ease was desirably correlated with all disease traits. Also, maternal stillbirth was favorably correlated with retained placenta. This suggests that cows with an easier and normal calving have fewer health problems afterward. Moderate genetic correlations between retained placenta and maternal calving difficulty and maternal stillbirth were reported recently by Koeck et al. (2014) in Canadian Holsteins.

Muscling was positively correlated with downer cow syndrome and mastitis, which suggest that cows with more muscling are more robust and healthy. Similar, Loker et al. (2012) found that a lower body condition score during the lactation was genetically associated with the occurrence of mastitis and metabolic disease.

In agreement with previous studies (e.g., Zwald et al., 2004; Holtsmark et al., 2008), longevity was favorably correlated with retained placenta, downer cow syndrome, and mastitis.

\section{Associations with Veterinarian Diagnoses}

Table 2 shows disease frequencies of cows from herds with both recording systems (farmer observations and veterinarian diagnoses). For both recording systems, disease frequencies for mastitis were almost identical,

Table 4. Heritabilities (on the diagonal; SE in parentheses) and genetic correlations (above the diagonal; SE in parentheses) for retained placenta, downer cow syndrome, and mastitis based on farmer observations (data set 1)

\begin{tabular}{lccc}
\hline Trait & $\begin{array}{c}\text { Retained } \\
\text { placenta }\end{array}$ & $\begin{array}{c}\text { Downer cow } \\
\text { syndrome }\end{array}$ & Mastitis \\
\hline Retained placenta & $0.011(0.002)$ & $-0.01(0.10)$ & $0.20(0.16)$ \\
Downer cow syndrome & & $0.031(0.003)$ & $0.18(0.14)$ \\
Mastitis & & & $0.003(0.001)$ \\
\hline
\end{tabular}


Table 5. Pearson correlations between estimated breeding values of sires with at least 30 daughters for retained placenta, downer cow syndrome, and mastitis based on farmer observations and routinely evaluated traits $(\mathrm{n}=598$ sires; data set 1$)$

\begin{tabular}{lccc}
\hline Trait & $\begin{array}{c}\text { Retained } \\
\text { placenta }\end{array}$ & $\begin{array}{c}\text { Downer cow } \\
\text { syndrome }\end{array}$ & Mastitis \\
\hline Milk yield & 0.01 & -0.02 & $-0.18^{* * *}$ \\
Protein yield & 0.02 & 0.02 & -0.08 \\
Fat yield & 0.03 & 0.05 & $-0.10^{*}$ \\
Somatic cell score & -0.003 & 0.07 & $0.27^{* * *}$ \\
Calving to first service & 0.03 & $0.16^{* * *}$ & -0.01 \\
56-d nonreturn rate & $0.11^{* *}$ & $-0.09^{*}$ & $0.13^{* *}$ \\
First service to conception & $0.13^{* *}$ & 0.05 & 0.07 \\
Calving ease direct & 0.03 & 0.04 & $-0.15^{* * *}$ \\
Calving ease maternal & $0.12^{* *}$ & $0.09^{*}$ & $0.11^{* *}$ \\
Stillbirth direct & 0.04 & 0.05 & -0.06 \\
Stillbirth maternal & $0.10^{*}$ & 0.07 & 0.03 \\
Longevity & $0.13^{* *}$ & $0.16^{* * *}$ & $0.15^{* * *}$ \\
Muscling & -0.05 & $0.14^{* * *}$ & $0.13^{* *}$ \\
\hline$* P<0.05, * * P<0.01, * * * P<0.001$ & \multicolumn{3}{c}{}
\end{tabular}

${ }^{*} P<0.05,{ }^{* *} P<0.01,{ }^{* * *} P<0.001$.

whereas for retained placenta and downer cow syndrome/milk fever disease frequencies were higher based on farmer observations. Higher disease frequencies based on farmer observations can be expected because mild disease cases may not be treated by a veterinarian. However, it should be also noted that veterinarian diagnoses are not always recorded comprehensively in the central dairy disease database and improvement is still needed (Egger-Danner et al., 2012, 2013), which could also be a reason for the lower disease frequencies. In the present study, it was also observed that data quality of farmer observations is in need of improvement. For example, $16 \%$ of cows with retained placenta had a veterinarian diagnosis but no corresponding farmer observation (result not shown). Information to increase awareness on the importance of the data to increase genetic gain for these traits could improve the motivation of recording high-quality data. Applications including these data for herd management could be a support as well.

Heritability estimates of farmer-observed health data were comparable with estimates based on veterinarian diagnoses. Genetic correlations between the investigated diseases based on farmer observations and veterinarian diagnoses were almost 1 , with estimates ranging from 0.98 to 0.99 (Table 6). As genetic correlations were close to 1 , farmer-recorded health data and veterinarian diagnoses were considered as the same traits in an additional analysis. This led to heritability estimates of $0.017,0.033$, and 0.011 for retained placenta, downer cow syndrome/milk fever, and mastitis, respectively (Table 7). These results suggest that farmer recorded health data could be used together with veterinarian diagnoses for genetic evaluations.

\section{Final Remarks}

Obtaining reliable breeding values for health traits is challenging. So far, direct health traits are included in the total merit index in Austria and Germany with a relatively low weight (Fuerst and Egger-Danner, 2014). The economic weights for early reproduction disorders plus ovarian cysts and for mastitis are currently 3.2 and $2.9 \%$, respectively. Thus, expansion of health data recording is required for a higher weight in the index and a higher impact with respect to selection response. Expansion of health data recording in regions with a low recording of veterinarian diagnoses could be achieved by the use of farmer observations. A high participation can be reached within a short time period. Currently, recording of farmer observations takes place in approximately $95 \%$ of all farms in Lower Austria and Upper Austria.

Until now, only farmer observations around calving have been recorded. Some diseases such as mastitis and lameness occur throughout lactation; therefore, a longer recording period would be important. Furthermore, the recording of additional traits, such as ketosis, metritis, and cystic ovaries, would be beneficial.

In Austria the recording of veterinarian diagnoses has priority because multidisciplinary use of the data and additional benefits are possible, but measures to improve data quantity need to be implemented. Based on the results of the present study, the additional use of farmer observations in genetic evaluations seems to be one possible way to achieve this goal.

Table 6. Heritabilities and genetic correlations ( $\mathrm{SE}$ in parentheses) for retained placenta, downer cow syndrome/milk fever, and mastitis based on farmer observations (farmer) and veterinarian diagnoses (vet; data set 2 )

\begin{tabular}{lccc}
\hline & \multicolumn{2}{c}{ Heritability } & Genetic \\
\cline { 2 - 3 } Trait & Farmer & Vet & correlation \\
\hline Retained placenta & $0.013(0.003)$ & $0.009(0.002)$ & $0.99(0.04)$ \\
Downer cow syndrome/milk fever & $0.030(0.004)$ & $0.013(0.002)$ & $0.99(0.03)$ \\
Mastitis & $0.005(0.002)$ & $0.012(0.003)$ & $0.98(0.06)$ \\
\hline
\end{tabular}


Table 7. Heritabilities (SE in parentheses) for combined traits (retained placenta, downer cow syndrome/milk fever, and mastitis) where farmer observations and veterinarian diagnoses were considered as the same trait (data set 2)

\begin{tabular}{ll}
\hline Trait & Heritability \\
\hline Retained placenta & $0.017(0.003)$ \\
Downer cow syndrome/milk fever & $0.033(0.005)$ \\
Mastitis & $0.011(0.003)$ \\
\hline
\end{tabular}

\section{ACKNOWLEDGMENTS}

We acknowledge the idea of Josef Miesenberger (OÖ Besamungsstation GmbH, Hohenzell and FIH, Ried, Austria) for recording of farmer-observed health data in conjunction with recording of calving ease. All farmers and veterinarians recording health data are gratefully acknowledged. This study is part of the project "OptiGene-Optimization of long-term genetic progress of Austrian cattle breeds with emphasis on health and genomic selection" funded by the Austrian Federal Ministry of Agriculture, Forestry, Environment and Water Management (Vienna); the Federations of Austrian Fleckvieh (Zwettl), Brown-Swiss (Innsbruck), Pinzgauer (Maishofen), Holstein (Leoben), and Tyrolean Grey Cattle (Innsbruck); the Federation of Austrian Cattle Breeders (Vienna); and cooperation with COMET K-Projekt "ADDA-Advancement of Dairying in Austria" (Vienna).

\section{REFERENCES}

Egger-Danner, C., B. Fuerst-Waltl, W. Obritzhauser, C. Fuerst, H Schwarzenbacher, B. Grassauer, M. Mayerhofer, and A. Koeck. 2012. Recording of direct health traits in Austria-Experience report with emphasis on aspects of availability for breeding purposes. J. Dairy Sci. 95:2765-2777.

Egger-Danner, C., W. Obritzhauser, C. Fuerst, B. Grassauer, K. Zottl, K. Fuchs, and B. Fuerst-Waltl. 2013. Aspects of validation and data quality based on veterinarian diagnoses. Pages 117-127 in Proc. ICAR Conference, Aarhus, Denmark. ICAR, Rome, Italy.

Egger-Danner, C., W. Obritzhauser, B. Fuerst-Waltl, B. Grassauer, R Janacek, F. Schallerl, C. Litzllachner, A. Koeck, M. Mayerhofer, J. Miesenberger, G. Schoder, F. Sturmlechner, A. Wagner, and K. Zottl. 2010. Registration of health traits in Austria: Experience review. Pages 69-77 in Proc. 37th ICAR Biennial Session, Riga, Latvia. ICAR, Rome, Italy.

Fuerst, C., and C. Egger-Danner. 2014. Inclusion of direct health traits in the total merit index of Fleckvieh and Brown Swiss cattle in Austria and Germany. Presentation at 39th ICAR Biennial Session, Berlin, Germany. Accessed Nov. 27, 2014. http://www.icar. org/Documents/Berlin_2014/PPTs/Presented/Egger-Danner.pdf.
Fuerst, C., A. Koeck, C. Egger-Danner, and B. Fuerst-Waltl. 2011. Routine genetic evaluation for direct health traits in Austria and Germany. Interbull Bull. 44:210-215.

Heringstad, B., Y. M. Chang, D. Gianola, and G. Klemetsdal. 2005. Genetic analysis of clinical mastitis, milk fever, ketosis, and retained placenta in three lactations of Norwegian Red cows. J. Dairy Sci. 88:3273-3281.

Holtsmark, M., B. Heringstad, P. Madsen, and J. Ødegård. 2008. Genetic relationship between culling, milk production, fertility, and health traits in Norwegian Red cows. J. Dairy Sci. 91:4006-4012.

Kadarmideen, H. N., R. Thompson, and G. Simm. 2000. Linear and threshold model genetic parameters for disease, fertility and milk production in dairy cattle. Anim. Sci. 71:411-419.

Koeck, A., C. Egger-Danner, C. Fuerst, W. Obritzhauser, and B. Fuerst-Waltl. 2010a. Genetic analysis of reproductive disorders and their relationship to fertility and milk yield in Austrian Fleckvieh dual-purpose cows. J. Dairy Sci. 93:2185-2194.

Koeck, A., B. Heringstad, C. Egger-Danner, C. Fuerst, and B. FuerstWaltl. 2010b. Comparison of different models for genetic analysis of clinical mastitis in Austrian Fleckvieh dual-purpose cows. J. Dairy Sci. 93:4351-4358.

Koeck, A., F. Miglior, J. Jamrozik, D. F. Kelton, and F. S. Schenkel. 2014. Genetic relationships of fertility disorders with reproductive traits in Canadian Holsteins. Paper 153 in Proc. 10th World Congress of Genetics Applied to Livestock Production, Vancouver, Canada.

Koeck, A., F. Miglior, D. F. Kelton, and F. S. Schenkel. 2012. Health recording in Canadian Holsteins: Data and genetic parameters. J. Dairy Sci. 95:4099-4108.

Loker, S., F. Miglior, A. Koeck, T. F. Neuenschwander, C. Bastin, J. Jamrozik, L. R. Schaeffer, and D. Kelton. 2012. Relationships between body condition score and health traits in first-lactation Canadian Holsteins. J. Dairy Sci. 95:6770-6780.

Madsen, P., and J. Jensen. 2008. A User's Guide to DMU. A package for analyzing multivariate mixed models. Version 6 , release 4.7. Danish Institute of Agricultural Sciences, Tjele, Denmark.

Negussie, E., I. Strandén, and E. A. Mäntysaari. 2008a. Genetic association of clinical mastitis with test-day somatic cell score and milk yield during first lactation of Finnish Ayrshire cows. J. Dairy Sci. 91:1189-1197.

Negussie, E., I. Strandén, and E. A. Mäntysaari. 2008b. Genetic analysis of liability to clinical mastitis, with somatic cell score and production traits using bivariate threshold-linear and linear-linear models. Livest. Sci. 117:52-59.

Neuenschwander, T. F.-O. 2010. Studies on disease resistance based on producer-recorded data in Canadian Holsteins. PhD thesis. University of Guelph, Guelph, Canada.

Onyiro, O. M., L. J. Andrews, and S. Brotherstone. 2008. Genetic parameters for digital dermatitis and correlations with locomotion, production, fertility traits, and longevity in Holstein-Friesian dairy cows. J. Dairy Sci. 91:4037-4046.

Stocker, F. 2008. Fitness-nur ein Schlagwort oder klarer wirtschaftlicher Nutzen. ZAR Seminar, March 13, 2008. Accessed Nov. 27, 2014. http://zar.at/Downloads/ZAR-Seminar.html.

ZuchtData. 2014. ZuchtData-Jahresbericht 2013 (Annual report about performance recording and cattle breeding in Austria). Accessed Nov. 27, 2014. http://zar.at/Downloads/Jahresberichte/ ZuchtData-Jahresberichte.html.

Zwald, N. R., K. A. Weigel, Y. M. Chang, R. D. Welper, and J. S. Clay. 2004. Genetic selection for health traits using producerrecorded data. II. Genetic correlations, disease probabilities, and relationships with existing traits. J. Dairy Sci. 87:4295-4302. 